\title{
Avaliação multitemporal da cobertura vegetal da reserva biológica de Tapirapé,
}

\section{Pará}

\author{
Multitemporal evaluation of the vegetation cover of the Tapirapé biological reserve, Pará \\ Evaluación multitemporal de la cobertura vegetal de la reserva biológica Tapirapé, Pará
}

Recebido: 27/03/2021 | Revisado: 08/04/2021 | Aceito: 10/04/2021 | Publicado: 20/04/2021

Erick dos Santos Ribeiro

ORCID: https://orcid.org/0000-0002-9204-366X

Universidade Federal Rural da Amazônia, Brasil

E-mail: erick.rib39@gmail.com

Barbara Luzia Santos de Oliveira Faro

ORCID: https://orcid.org/0000-0002-8764-7274 Universidade do Estado do Pará, Brasil

E-mail: barbarafaro7@gmail.com

Raqueli Solange Corrêa Nascimento

ORCID: https://orcid.org/0000-0003-3177-1337 Universidade do Federal do Pará, Brasil

E-mail: raquelisolange@ hotmail.com

Francimary da Silva Carneiro

ORCID: https://orcid.org/0000-0002-1693-8779

Secretaria de Estado de Meio Ambiente e Sustentabilidade, Brasil

E-mail: francimarycarneiro@gmail.com

Ana Paula Magno do Amaral

ORCID: https://orcid.org/0000-0002-1749-791X

Secretaria de Estado de Meio Ambiente e Sustentabilidade, Brasil

E-mail: magno_ana@yahoo.com.br

Matheus Gerhardt dos Santos Bezerra

ORCID: https://orcid.org/0000-0003-3804-6963

Secretaria de Estado de Meio Ambiente e Sustentabilidade, Brasil

E-mail: matheus.gerhardt92@gmail.com

Marcio Braga Amorim

ORCID: https://orcid.org/0000-0001-7508-2766

Secretaria de Estado de Meio Ambiente e Sustentabilidade, Brasil E-mail: marciobamorim@gmail.com

Thales de Souza Garcia

ORCID: https://orcid.org/0000-0001-6046-7743

Secretaria de Estado de Meio Ambiente e Sustentabilidade, Brasil

E-mail:thalesg25@gmail.com

\begin{abstract}
Resumo
O presente trabalho busca analisar a multitemporalidade da cobertura vegetal da Biológica (REBIO) de Tapirapé nos anos de 2013 e 2018. Para processamento digital foi utilizado imagens do satélite Landsat 8 de 14/06/2013 e 03/08/2018, sensor espectral OLI e termal TIRS o datum de referência WGS 1984 e no fuso $22 \mathrm{~S}$ os procedimentos utilizou o software ArcGis 10.5. Para realização do NDVI os valores foram agrupados em quatro classes: corpos hídricos, solo exposto, floresta ombrófila aberta e floresta ombrófila fechada e seus respectivos alvos de superfície identificados pela alteração nas reflectâncias, de modo que quanto mais próximo de +1 , maior a densidade da vegetação e quando próximo de -1 menos densa. Os resultados demostraram diferença na cobertura vegetal ao logo dos anos. A classe 1 apresentou valores negativos de $(-0,16)$ e $(-0,18)$ não refletida devido ao rio Tapirapé em comparação a 2013 houve um aumento de $23,7 \%$ na presença de corpos d'água na reserva. A classe 2 com valor de 0,31 de refletância ocorrendo uma diminuição de $5,8 \%$ de solo exposto em 2018. A classe $3(0,44)$ demostrou $1,5 \%$ de crescimento da vegetação rasteira. A classe 4 , expressou um aumento de $1 \%$ de vegetação.
\end{abstract}

Palavras-chave: Unidade de conservação; Floresta úmida amazônica; Conservação da biodiversidade.

\begin{abstract}
The present work seeks to analyze the multitemporality of the Tapirapé Biological Plant Cover (REBIO) in the years 2013 and 2018. For digital processing, images from the Landsat 8 satellite of 06/14/2013 and 08/03/2018, OLI spectral sensor were used. and thermal TIRS the reference datum WGS 1984 and in the spindle 22S the procedures used the software ArcGis 10.5. In order to carry out the NDVI, the values were grouped into four classes: water bodies, exposed soil, open rainforest and closed rainforest and their respective surface targets identified by the change in reflectance, so that the closer to +1 , the greater the density vegetation and when close to -1 less dense. The results
\end{abstract}


showed a difference in vegetation cover over the years. Class 1 showed negative values of $(-0.16)$ and $(-0.18)$ not reflected due to the Tapirapé river compared to 2013 there was an increase of $23.7 \%$ in the presence of bodies of water in the reserve. Class 2 with a 0.31 reflectance value, with a decrease of $5.8 \%$ in exposed soil in 2018 . Class 3 (0.44) showed $1.5 \%$ growth of undergrowth. Class 4, expressed an increase of $1 \%$ in vegetation.

Keywords: Conservation unit; Amazon rainforest; Conservation of biodiversity.

\section{Resumen}

El presente trabajo busca analizar la multitemporalidad de la Cobertura Vegetal Biológica Tapirapé (REBIO) en los años 2013 y 2018. Para procesamiento digital, imágenes del satélite Landsat 8 del 14/06/2013 y 03/08/2018, sensor espectral OLI y térmico TIRS el datum de referencia WGS 1984 y en el husillo 22S los procedimientos utilizaron el software ArcGis 10.5. Para realizar el NDVI, los valores se agruparon en cuatro clases: cuerpos de agua, suelo expuesto, bosque lluvioso abierto y bosque lluvioso cerrado y sus respectivos objetivos superficiales identificados por el cambio de reflectancia, de manera que cuanto más cerca de +1 , el mayor densidad de vegetación y cuando está cerca de -1 menos densa. Los resultados mostraron una diferencia en la cobertura vegetal a lo largo de los años. La clase 1 presentó valores negativos de $(-0,16)$ y $(-0,18)$ no reflejados debido al río Tapirapé respecto a 2013 hubo un incremento de $23,7 \%$ en presencia de cuerpos de agua en la reserva. Clase 2 con un valor de reflectancia de 0.31 , con una disminución de 5.8\% en suelo expuesto en 2018. La Clase $3(0.44)$ mostró $1.5 \%$ de crecimiento de sotobosque. Clase 4, expresó un aumento del $1 \%$ en vegetación.

Palabras clave: Unidad de conservación; Selva amazónica; Conservación de la biodiversidad.

\section{Introdução}

O bioma Amazônia é um ecossistema singular reconhecido internacionalmente pela maior floresta tropical do mundo com elevada riqueza de recursos naturais e diversidade biológica (Amin, 2015). A floresta abrange nove países da América do Sul cerca de $60 \%$ da vegetação encontra-se em território Brasileiro nos estados da região norte (Acre, Amapá, Amazonas, Pará, Roraima Rondônia e Tocantins), além do Maranhã e Mato Grosso repercutindo no papel fundamental do país na gestão deste ecossistema (Ab’Saber, 1977, Pinheiro et al, 2021).

O debate acerca das questões econômicas e ambientais da Amazônia é pauta importante na política interna e externa do país, desde o período colonial a região é alvo de interesse mundial (Loureiro, 2002). O século XX trouxe reflexões a respeito do modo de consumo da população mundial e grande preocupação com o meio ambiente resultando em conferências mundiais tendo como foco o desenvolvimento sustentável (Silva, 2008; Bezerra, 2012).

Entretanto, o crescimento das atividades antrópica aos longos dos anos vem aumentado drasticamente os impactos nas áreas verdes, na forma de ocupação do solo, alterando de maneira intensa os ecossistemas naturais (Davidson \& Artaxo, 2004). Ademais a forma tradicional de ocupação ocasiona cada vez mais a necessidade da expansão dos espaços urbano, abertura de estradas, além do aumento da fronteira agrícola diversos são fatores de natureza complexas que resultam na supressão das florestas em larga escala (Alencar, 2004; Rosário, 2021).

Este cenário tem se agravado também com as grandes queimadas oriundas do período de estiagem severa na região e juntamente com os incêndios criminosos, acredita-se que cerca de 529 quilômetros quadrados de vegetação tenham sido perdidos nos primeiros 4 meses do ano de 2020, um aumento de 171\% em comparação ao mesmo período em 2019 (Fonseca et al., 2020). A perda de vegetação não ocasiona somente degradação ao meio ambiente com a perda de fauna e flora, mas acarreta danos diretos e indiretos ao homem como o aumento de doenças e prejuízos a oferta dos serviços ecossistêmicos (Alho, 2012, Carneiro, 2020).

Fonseca (2020), afirma que o Pará é o estado com maior taxa de desmatamento do país, a destruição das florestas paraense corresponde a $37 \%$ do que foi desmatado em toda região norte. Esses dados são alarmantes, pois pesquisa realizados pelo Instituto do Homem e Meio Ambiente da Amazônia constataram que o Pará lidera o ranking dos estados com risco iminente de desmatamento no interior de áreas protegidas.

As áreas protegidas é uma estratégia importante na tentativa desacelerar o desmatamento da Amazônia, o Sistema Nacional de Unidade de Conservação da Natureza (SNUC) foi criado pela Lei Federal nº 9.985/00 (Brasil, 2000). Seu objetivo 
é a demarcação de área prioritária para a preservação e conservação da flora e fauna. As unidades estão divididas em duas categorias em áreas de uso sustentável que permite a exploração planejada garantido o equilíbrio ecológico e a de proteção integral destinada a proteção absoluta da Fauna e flora (Brasil, 2000).

Essas áreas resguardam espécies amaçadas de extinção como a Reserva Biológica (REBIO) de Tapirapé que apresenta alta diversidade de espécies de aves, mamíferos, anfíbios, répteis (Bernardo et al., 2012) e presença das espécies mais relevantes das famílias botânicas da Amazônia.

De acordo com Ferreira et al., (2005) a proporção de desmatamento em áreas protegida é de 1,5\% a 4,7\%, já nas áreas que não são protegidas, ou seja, fora essa proporção chega a $29,2 \%$ a 48,1\%, demostrando claramente a importância das unidades. Contudo, essas áreas estão sujeitas ao desmatamento, como exemplo a REBIO de Gurupi no maranhão que enfrenta sérios problemas ambientais em 2017 perdeu equivalente 22 mil hectares de vegetação densa devido o avanço de propriedades em torno da área, incêndios e a extração ilegal madeireira (ICMBIO, 2015; Silva et al., 2019).

Os sensores de satélite são ferramentas essências no reconhecimento de áreas desmatadas, focos de incêndios e índice de vegetação, além de ajudarem no levantamento de dados, monitoramento das florestas e estudos do tempo e espaço geográfico, (LIMA, 2018). A utilização de uma série temporal de imagens permite a confecção de diversos mapas de uso da terra o que possibilita comparações entre os mesmos a quantificação das alterações ocorridas nessas porções do ambiente permitindo o monitoramento de áreas florestais quanto às suas taxas de manutenção, redução ou expansão (Facco, 2016).

Diante dos desafios recorrentes na atualidade com aumento do desmatamento na Amazônia o presente trabalho busca analisar a dinâmica da cobertura vegetal da Reserva Biológica Tapirapé no município de Marabá no estado do Pará.

\section{Metodologia}

A área em estudo localiza-se na Reserva Biológica Tapirapé, unidade de conservação brasileira localizada no município de Marabá no estado do Pará (Figura1). Na Latitude Sul 05³0'13" e Longitude Oeste 50¹6'44", criado pelo decreto № 97.719, de 5 de maio de 1989. Caracterizada pelo bioma da floresta úmida amazônica. Além disso, abriga espécies ameaçadas de extinção, como a jaguatirica e a onça pintada (ICMBio, 2020).

Para processamento digital foi utilizado duas imagens do satélite Landsat 8, sensor OLI cenas - 223/061 de 14/06/2018 e 03/08/2018, sensor espectral OLI (Operation Land Imager) e termal TIRS (ThermalInfrared Sensor) disponibilizada pelo Instituto Nacional de Pesquisas Espaciais - INPE o datum de referência WGS 1984 (World Geodetic System) e no fuso $22 \mathrm{~S}$ os procedimentos foram realizados em ambiente SIG, utilizando o software ArcGis 10.5. 
Figura 1. Mapa de localização da Reserva Biológica Tapirapé.

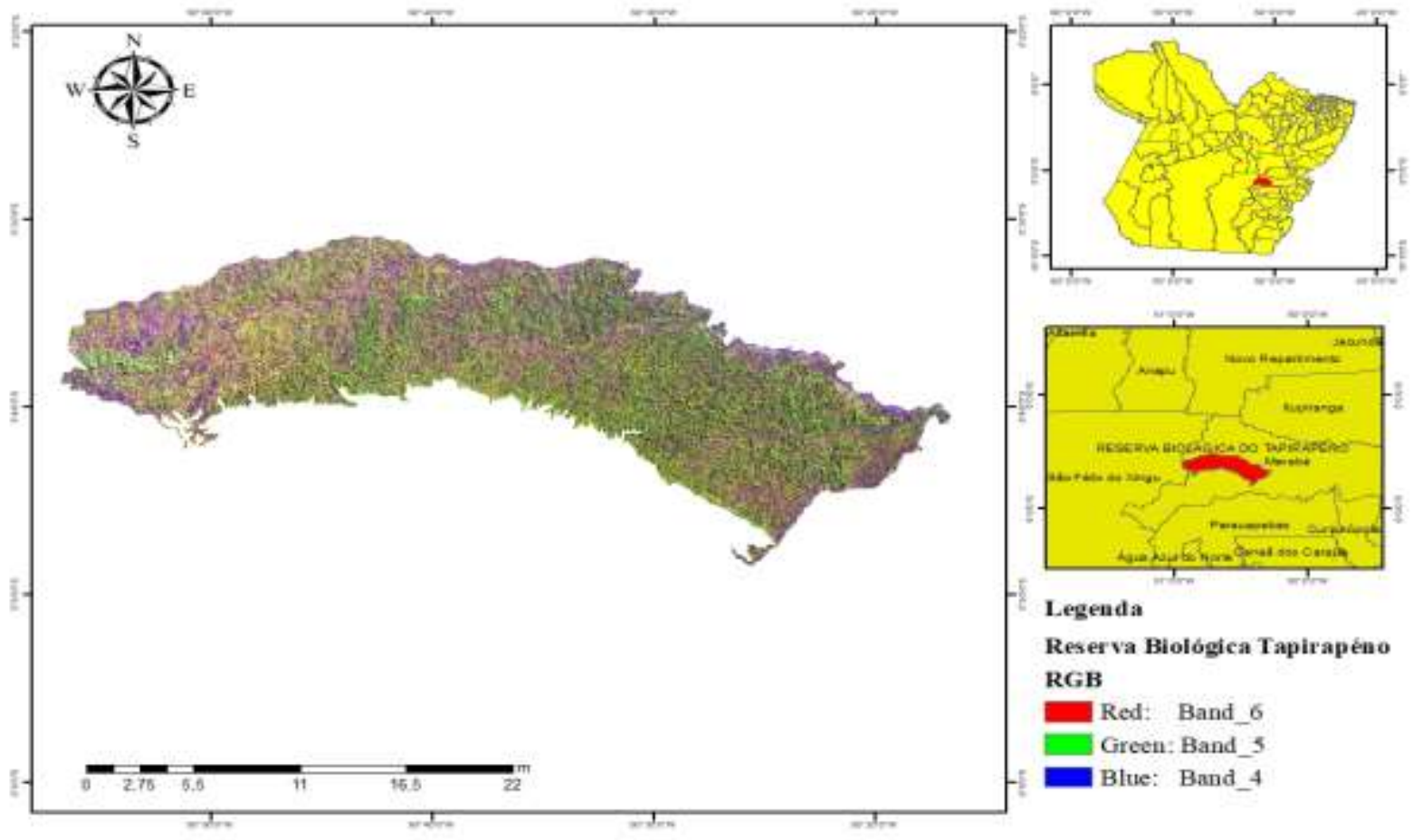

Fonte: Autores (2020).

Para realização do NDVI, foi aplicado o algoritmo (ROUSE et al., 1973) que consiste na diferença da refletância no infravermelho próximo e a refletância no vermelho dividido pela soma dessas duas bandas como mostra a seguinte equação:

$\mathrm{NDVI}=((R i v p-R v) /(R i v p+R v))$

Onde:

$\mathrm{R}=$ refletância;

ivp = espectro eletromagnético infravermelho;

$\mathrm{v}=$ espectro eletromagnético vermelho.

$\mathrm{Na}$ etapa de análise para identificação das radiações espectrais que representam a energia solar refletida por cada pixel, por unidade de área, de tempo, do ângulo sólido e do comprimento de onda, medida nos sensores a bordo do satélite, que no caso do Landsat 8 sensor OLI, correspondem as medidas realizadas nos canais 1, 2, 3, 4, 5 e 6 (Tabela 1).

Tabela 1. Características espectrais dos instrumentos imageadores OLI e TIRS.

\begin{tabular}{lcc}
\hline Landsat-8 Bands & $\begin{array}{c}\text { Comprimento de onda } \\
\text { (micrômetros) }\end{array}$ & $\begin{array}{c}\text { Resolução } \\
\text { (metros) }\end{array}$ \\
\hline Band 1 - Coastal aerosol & $0.43-0.45$ & 30 \\
Band 2 - Blue & $0.45-0.51$ & 30 \\
Band 3 - Green & $0.53-0.59$ & 30 \\
Band 4 - Red & $0.64-0.67$ & 30 \\
Band 5 - Near Infrared (NIR) & $0.85-0.88$ & 30 \\
Band 6 - SWIR 1 & $1.57-1.65$ & 30 \\
\hline
\end{tabular}


O produto obtido foi dividido em 4 intervalos de reflectância nos dois mapas (Tabela 2), pois essa quantidade de intervalos exibiu o melhor agrupamento das classes de acordo com a resposta espectral dos alvos, variado de -0,24 a 0,61 por pixel, de modo que quanto mais próximo de +1 , maior a densidade da vegetação sendo que a medida em que esse valor diminui, a vegetação vai ficando mais rala próxima de -1, maior indício de alteração na vegetação.

Tabela 2. Intervalos das respectivas classes e alvos de superfície do NDVI.

\begin{tabular}{lcc}
\hline Intervalos de NDVI & Classes & Alvos de superfície \\
\hline Classes 1 & Corpos hídricos \\
Classes 2 & Solo exposto \\
Classes 3 & Vegetação ombrófila aberta \\
Classes 4 & Vegetação ombrófila Fechada \\
\hline
\end{tabular}

Fonte: Autores (2020).

Esse método consiste de a vegetação fotossinteticamente ativa estará se utilizando da luz no comprimento de onda compreendido pelo vermelho, mas como não faz uso do infravermelho próximo, estará refletindo-a. Do uso destes parâmetros de reflectância obter-se-á um índice, o NDVI. Longo após foi feito sobreposição do arquivo shapefile da reserva biológica para realizar o corte da área de interesse com a ferramenta clip no software Arcgis 10.5 o corte da imagem.tiff para destaque do local da pesquisa.

\section{Resultados e Discussão}

Através do produto gerado pelo NDVI, foi possível observar as diferenças na variação da cobertura vegetal ao entre o período de 2013 à 2018, nas duas imagens os elementos visuais mais representativos são os de valores positivos, o que sugere a aumento na presença de cobertura vegetal. Os valores de NDVI foram agrupados em quatro classes e seus respectivos alvos de superfície identificados pela alteração nas reflectâncias subdivididos em corpos hídricos, solo exposto, floresta ombrófila aberta e floresta ombrófila fechada (Figura 2 e Figura 3).

Figura 2. Índice de vegetação da diferença normalizada da reserva biológica Tapirapé, período de 2013.

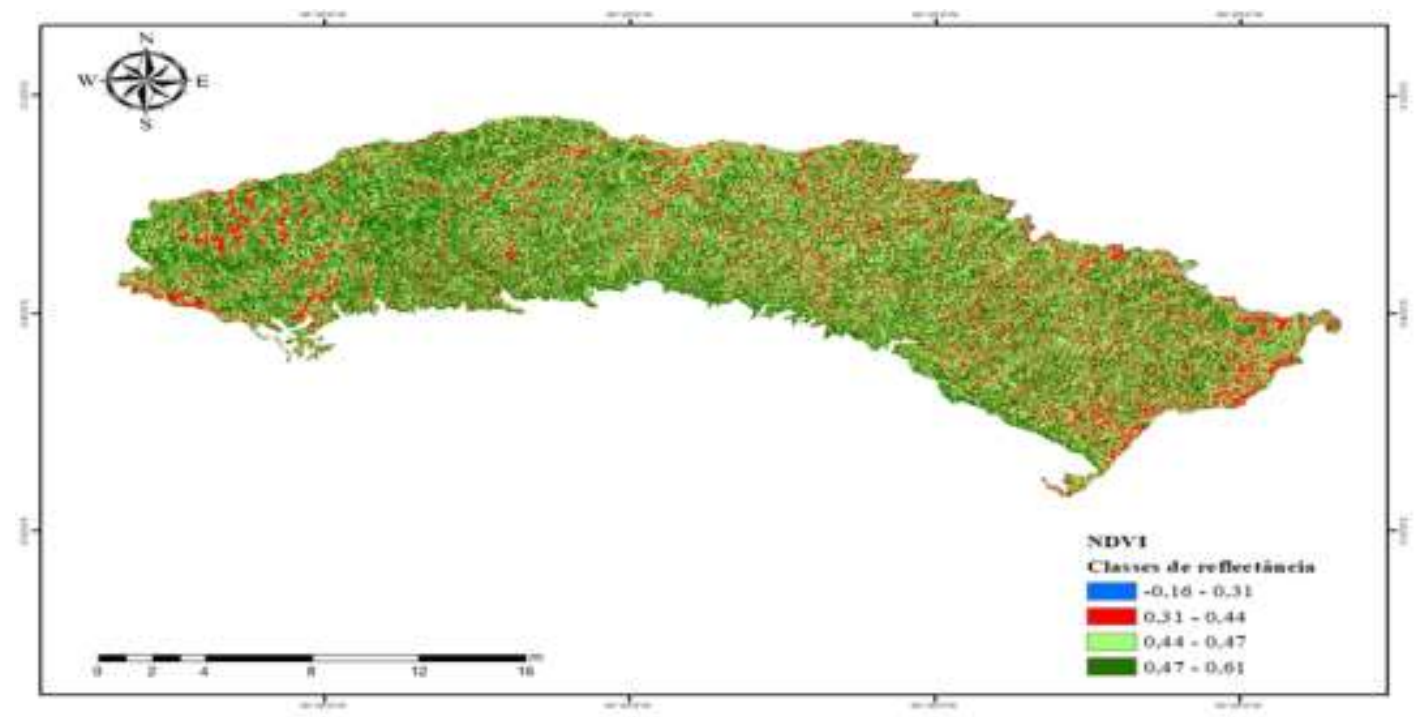

Fonte: Autores (2020). 
Figura 3. Índice de vegetação da diferença normalizada da reserva biológica Tapirapé, período de 2018.

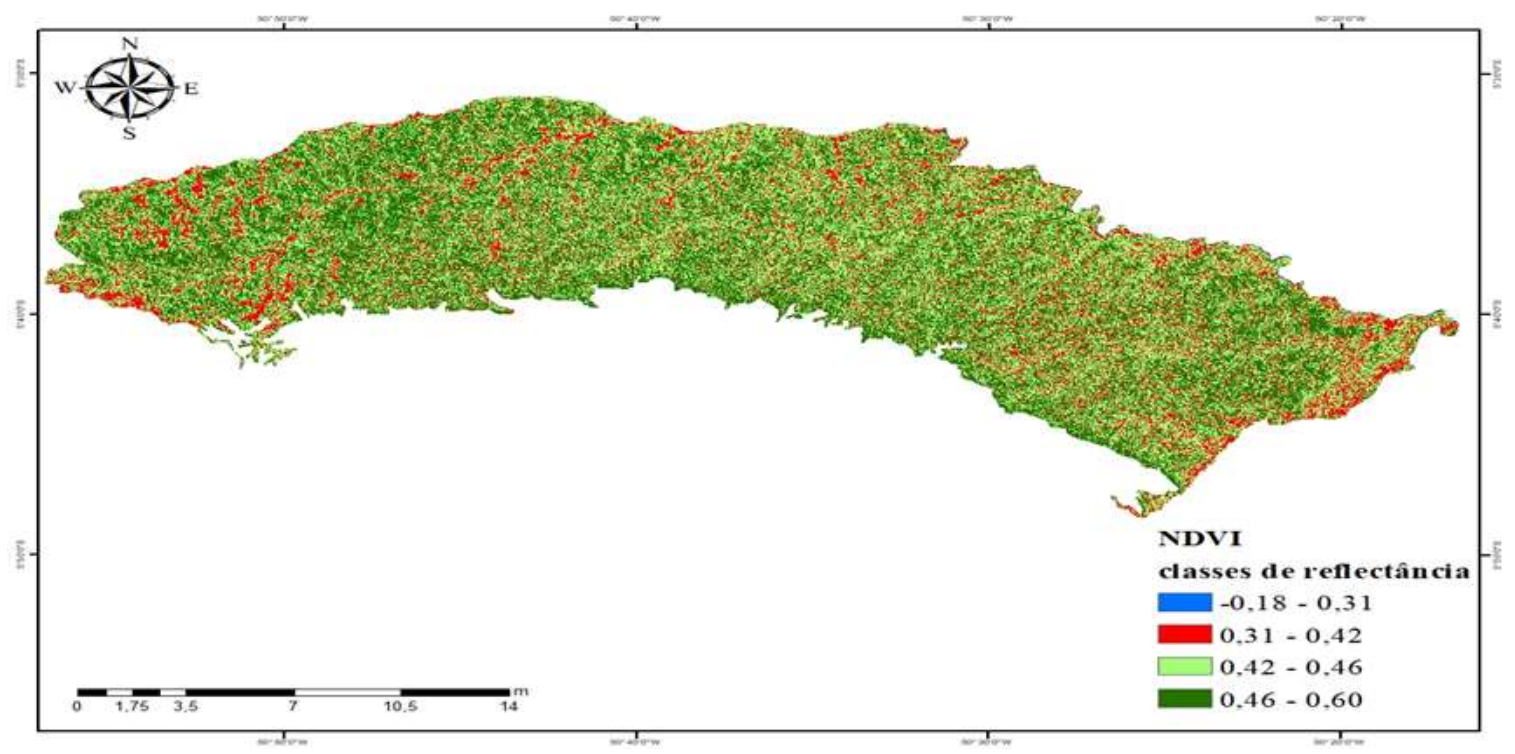

Fonte: Autores (2020).

Os valores negativos são representados pela classe $1(-0,16)$ e $(-0,18)$ expondo a presença de corpo hídrico com fluxo incidente sobre a água pura não refletida ocasionado pela presença do rio Tapirapé, houve um aumento de 23,7\% na presença de corpos d'água na reserva de acordo com a análise multitemporal. Um trabalho realizado na ilha de colares utilizado o NDVI foi possível observa distribuição dos corpos hídricos e a forma de ocupação do solo presente no território (Ribeiro, 2019). Em estudo realizado executado com NDVI na microbacia hidrográfica do riacho dos cavalos, Crateús-CE, demostrou que as áreas próximas açudes sofrem maior impacto com a supressão da cobertura vegetal, uma vez que contribuem para o adensamento populacional e exploração dos recursos naturas, seja através da agricultura irrigada ou pecuária (Oliveira, 2011). Uma pesquisa realizada na avaliação de cobertura vegetal em áreas de preservação permanente em Mojuí dos Campos - PA, observou que nas APPs a maior classe era de vegetação densa com 43\%, foi identificado conflito de uso da terra nesta zona, pois apresentam porções de áreas degradas e sem cobertura vegetal, representando 19,34\% do total, ou seja, (SEMAS, 2021).

A classe 2 com valor centralizado em $(0,31)$ assim como a 1, correspondente a locais descobertos como bacos de areia, rochas, localidade desmatamentos e outras áreas sem vegetação, interpretando pela cor vermelha, de acordo com os resultados obtidos dos mapas se observa-se uma diminuição de 5,8 \% de solo exposto em 2018. Um trabalho realizado na Reserva Biológica Guaribas Paraíba - PB, utilizado o NDVI foi possível identificar peculiaridades na vegetação variando entre os tons de verde claro e escuro e alvos na superfície, representados pela cor roxa, indicado diminuição das áreas de sucessão intermediaria e aumento de solo exposto (Lima, 2018).

A temática da classe 3 apresentou valores de reflectância agrupados entre $(0,44)$ e $(0,46)$ demostra vegetação de crescimento espontâneo demostrado floresta ombrofila aberta, de cobertura vegetal superior a classe 2 com aumento de 1,5\% de 2013 para 2018 (Tabela 3), sendo ainda incipiente no que diz respeito a atividade fotossintética e presença de clorofila, de acordo com os parâmetros deste índice. Que pode estar associado a organismos de pequeno porte como arbustos e plantas herbáceas características de área em regeneração. Em um mapeamento no cerrado da Reserva Biológica da Contagem, foi possível gerar grande número classes de reflectância indicando alta diversidade fitofisionômica (Lopes, 2009). 
Tabela 3. Área das classes com incremento ou redução em porcentagem.

\begin{tabular}{lccc}
\hline & $\mathbf{2 0 1 3}$ & $\mathbf{2 0 1 8}$ & \\
\hline Classes & Área $\left(\mathrm{m}^{2}\right)$ & Área $\left(\mathrm{m}^{2}\right)$ & \% \\
Água & 1252 & 1640 & Aumento de 23,7 \\
Solo exposto & 216466 & 204664 & Diminuição de 5,8 \\
Floresta Ombrofila Aberta & 478760 & 486140 & Aumento de 1,5 \\
Floresta Ombrofila Fechada & 405705 & 409753 & Aumento de 1,0 \\
\hline
\end{tabular}

Fonte: Autores (2020).

Na última classe 4 são demostrados grande expressão de acordo com o mapa de NDVI no valor de $(0,60)$ a $(0,61$, representado a floresta ombrofila fechada, demostrado áreas de vegetação verde de maior atividade fotossintética e densa, como sugere o índice, uma vegetação perenifólia, cujas folhas são mantidas durante todo o ano, sendo essencial seu zoneamento e preservação ambiental, houve um pequeno aumento de um $1 \%$ nesta classe (Tabela 3). Na aplicação de uma técnica de agrupamento, baseada no padrão temporal em uma série de imagens sequenciais de NDVI, permitiu gerar padrão fenológico típico e distinto entre as regiões homogêneas Reserva do Niassa norte de Moçambique (Nhongo, 2017). Nas estratégias de implantação de um manejo florestal sustentável em pequenas propriedades rurais no Centro-Sul do Paraná observou-se na primeira verificação no ano de 2011 uma ocupação vegetal de baixa densidade e arredores uma ocupação de média densidade. Ao verificar a mesma área no ano de 2014 a região com uma ocupação vegetal de baixa densidade, teve um ganho expressivo de ocupação e densidade vegetal (Lima, 2017).

O presente trabalho demostrou grande importância na descrição do comportamento da vegetação e sua caracterização ao logo da reserva biológica mostrando a viabilidade do NDVI no monitoramento na área de preservação no ambiente Amazônico. Em uma análise semelhante utilizando o índice de vegetação aplicado através do geoprocessamento comprovou a viabilidade da utilização de imagens de satélite para mapear a cobertura vegetal no ecossistema de Caatinga, como também de base para desenvolver pesquisas científicas (Oliveira, 2019).

A cobertura vegetal de Tapirapé em sua totalidade encontra-se preservada, isso deve-se a presença e atuação do Iderflor, além das parcerias com instituições públicas de ensino como a Universidade Federal do sul e sudeste do Pará (Unifesspa) no qual desenvolve programas e projetos que reúne professores e os residentes no entorno da reserva como o “ Programa de Educação, Agricultura Familiar e Conservação da Biodiversidade", iniciativas que aumentam o conhecimento e a participação coletiva sobre a reserva (UNIFFESPA, 2017). De acordo com Loureiro (2014), a gestão participativa é um processo que resulta na relação de diversos atores socias, essa interação é fundamental para a manutenção das unidades de conservação.

Os Projetos de Monitoramento de mamíferos, Ecologia e Taxonomia na ReBio Tapirapés e Monitoramento da fauna de solo na Flona Tapirapé-Aquiri, são executados pela instituição e conta com seminários para divulgação dos resultados das pesquisas realizadas na reserva, os dados científicos reafirmam a importância da unidade para a conservação de fauna e flora da região (UNIFFESPA, 2017). Portanto, a reserva é exemplo de que uma boa gestão participativa onde os diversos setores sociais estão interligados.

\section{Conclusão}

A partir dos resultados observou-se aumento da refletância ao logo dos anos de 2013 a 2018 que expressa grande destaque da vegetação na reserva, podendo estar associado a regeneração da vegetação, permitido inferir positivamente que os 
trabalhos realizados pelas organizações e instituições na região tem permitido a conservação do ecossistema e o equilíbrio ambiental da unidade.

A técnica de NDVI é um parâmetro de estudo para possíveis impactos e suas peculiaridades ambientais em áreas de preservação, tornando-se uma importante ferramenta no monitoramento e análise do estado de conservação das áreas destinadas à preservação dos ambientes naturais, além de ser instrumento essencial na tomada de decisão na gestão das Unidades de conservação.

\section{Referências}

Ab'saber, A. N. (1977). Os domínios morfoclimáticos na América do Sul: Primeira aproximação. Geomorfologia, 52 , 1-22.

Alencar, A., Nepstad, N, Mcgrath, D, Moutinho, P, Pacheco, P, Diaz, M. D. C. V. E. \& Filho, B. S. (2004). Desmatamento na Amazônia: indo além da emergência crônica. Manaus, Instituto de Pesquisa Ambiental da Amazônia (Ipam), p. 89.

Alho, C. J. R. (2012). Importância da biodiversidade para a saúde humana: uma perspectiva ecológica. Estudos avançados, 26(74), 151-165.

Amin, M. G. (2015). A Amazônia na geopolítica mundial dos recursos estratégicos do século XXI. Revista Crítica de Ciências Sociais, 107, 17-38.

Arana, A. (2009). A composição elementar do aerossol atmosférico em Manaus e Balbina. Dissertação (Mestrado em Clima e Ambiente) - Instituto de Pesquisas da Amazônia INPA, Manaus, p.89.

Bernardo, P. H., Guerra-Fuentes R.A., Matiazzi, W., \& Zaher, H. (2012). Checklist of Amphibians and Reptiles of Reserva Biológica do Tapirapé, Pará, Brazil. Check List, 8(5), 839-846.

Bezerra, J. A. (2012). Amazônia na Rio+20: as discussões sobre florestas na esfera internacional e seu papel na Rio+20. Caderno EBAPE.BR, 10(3).

Brasil. (2000). SNUC - LEI No 9.985, DE 18 DE JULHO DE 2000. http://www.planalto.gov.br/ccivil_03/leis/L9985.htm.

Carneiro, F. S., Ruschel, A. R., Oliveira, F. A. O., Soares, M. H. M., Rodrigues, C. F. A. \& Pinto, M. V. P. (2020). Resiliência da Biomassa Acima do Solo em Áreas Experimentais na Amazônia Oriental. Biodiversidade Brasileira, p. 74-83.

Facco, D. S, Benedett, A. C. P, Filho, W. P, Kaiser, E. A.\& Osto, J. V. D. (2016). Geotecnologias para monitoramento florestal no município de Nova Palma Rio Grande Do Sul - BR. Revista Eletrônica em Gestão, Educação e Tecnologia Ambiental Santa Maria, 20(1), 417-426.

Ferreira, L. V, Venticinque, E. \& Almeida, S. A. (2005). O desmatamento na Amazônia e a importância das áreas protegidas. Estudos Avançados, 19(53), $157-166$.

Fonseca, A., Amorim, L., Cardoso, D., Ribeiro, J., Ferreira, R., Kirchhoff, F., Monteiro, A., Santos, B., Ferreira, B., Souza Jr., C., \& Veríssimo, A. (2020). Boletim do desmatamento da Amazônia Legal (setembro 2020) SAD (p. 1). Imazon. https://imazon.org.br/publicacoes/boletim-do-desmatamento-daamazonia-legal-setembro-2020-sad/.

Hrycyk, P, Pinho, R. L. \& Korzekwa, J. (2017). Influência do desmatamento no clima da região de alta floresta - MT. Revista Eletrônica da Faculdade de Direito de Alta Floresta - MT. 6(2).

ICMBio- Instituto Chico Mendes. (2020). https://www.icmbio.gov.br/portal/unidades-de-conservacao-amazonia/2000-rebio-do-tapirape.

ICMBio. (2020). Plano de Manejo. http://www. Icmbio.gov.br/portal/unidadesdeconservacao/biomasbrasileiros/amazonia/unidades-de-conservaçãoamazonia/2000_rebio_do_tapirape_3.pdf.

Lima, B. M, Braga, N. S, Lobato, W. T. S, Junior, M. V. R. O. \& Ferreira, B. M. (2018). Índice de vegetação por diferença normalizada (Ndvi) Para Análise De Cobertura Vegetal Na Rebio Guaribas, Paraíba - PB. In: III Congresso Internacional das Ciências Agráias, João Pessoa - PB. Anais do Congresso Internacional das Ciências Agrárias.

Lima, D. R. M, Dlugosz, F. L, Iurk, M. C. \& Pesck, V. A.: (2017). Uso de NDVI e SAVI para Caracterização da Cobertura da Terra e Análise Temporal em Imagens RapidEye. Revista Espacios. 38(36), 1-15.

Lima, S. C, Lima, F. C, Basílio, R. F. \& Neto, J. M. M. (2018). Geoprocessamento na análise espaço-temporal da cobertura vegetal do município de Seridó PB. Revista Científica da Faculdade de Educação e Meio Ambiente. Ariquemes: FAEMA, 9(1).

Lopes, G. O, Ribeiro, C. F. D. A. \& Silva, W. B. (2009). Mapeamento das fitofisionomias de cerrado da Reserva Biológica da Contagem, DF, por meio de sensoriamento remoto. In: XIV Simpósio Brasileiro de Sensoriamento Remoto, Natal, Brasil. Anais Simpósio Brasileiro de Sensoriamento Remoto.

Loureiro, V.K. (2002). Amazônia: uma história de perdas e danos, um futuro a (re)construir. Estudos Avançados, $16(45), 107$ - 12.

Neto, J. M. M, Pereira, J. S, Bezerra, A. E, Silva, M. J. \& Sena, J. P. O. (2018). Análise das classes de cobertura vegetal no município de Taperoá - Paraíba. In: Congresso Técnico Científico da Engenharia e da Agronomia- CONTECC, Maceió - AL. Anais Congresso Técnico Científico da Engenharia e da Agronomia.

Nhongo, E. J. S, Fontana, D. C, Guasselli, L. A. \& Esquerdo, J. C. D. M. (2017). Caracterização fenológica da cobertura vegetal com base em série temporal NDVI/MODIS na reserva do Niassa - Moçambique. Revista Brasileira de Cartografia. 6(69), 1175-1187. 
Research, Society and Development, v. 10, n. 4, e50910414345, 2021

(CC BY 4.0) | ISSN 2525-3409 | DOI: http://dx.doi.org/10.33448/rsd-v10i4.14345

Oliveira, J. G. B, Sales, M. C. L. \& Melo, E. T.: (2011). Aplicação do índice de vegetação por diferença normalizada (NDVi) para análise da degradação ambiental da microbacia hidrográfica do riacho dos cavalos, Crateús-CE. Raega - O Espaço Geográfico em Análise, 23.

Oliveira, P. J. L, Filho, C. R. S, Júnior, I. R. M, Oliveira, A. M. \& Costa, D. F. S. (2019). Análise multitemporal na cobertura vegetal da RPPN Stoessel de Brito, Jucurutu, RN, Brasil. In: XVIII Simpósio Brasileiro de geográfia e fisíca aplicada, Fortaleza-CE. Anais Simpósio Brasileiro de geográfia e fisíca aplicada.

Pinheiro, K. A. O., Ruschel, A. R., Carneiro, F. S., Frazão, A. S., Souza, M. F. S., D’Arace, L. M. B. \& Amorim, M. B. (2021). Potencial de espécies comerciais analisado pelo índice de valor de importância em área de exploração de impacto reduzido. Research, society and development, 10 , e16610212292.

Ribeiro, E. S, Araújo, A. L.F, Sousa, M. C, Castro, R. J. \& Santos, M. A. F. (2019). Análise da distribuição espacial da cobertura vegetal na ilha de Colares PA. In: XII Seminário Internacional de Desenvolvimento Rural Sustentável, Cooperativismo e Economia Solidária (XII SICOOPES), 2019, Pará. Caderno de Resumos. Pará - PA. Instituto Federal de Educação, Ciência e Tecnologia do Pará, 1. 28-29.

Rosário, R. R., Barbosa, M. T., Carneiro, F. S. \& Costa, M. S. S. (2021). Uso e ocupação do solo do município de novo progresso no Estado do Pará-Brasil. Research, society and development, 10, e51210112060-e51210112060.

SEMAS - Secretaria de Estado de Meio Ambiente e Sustentabilidade. ( 2021). https://www.semas.pa.gov.br/revistaseaf/edicoes.pdf.

Silva, A. C. S. (2008.). Uma abordagem neo-institucionalista sobre a atuação do tratado de cooperação amazônica na Amazônia Continental. Monografia do curso de Relações Internacionais - Universidade de Brasília (UNB).

UNIFESSPA. (2017). Seminário apresenta resultados de projetos da Unifesspa e ICMBio na reserva Tapirapé. Uniffesspa, https://www.unifesspa.edu.br/noticias/1831-seminario-apresenta-resultados-de-projetos-desenvolvidos-pela-unifesspa-e-icmbio-na-reserva-tapirape. 